\title{
Thermal-Mechanical Cyclic Test of a Composite Cryogenic Tank for Reusable Launch Vehicles
}

\author{
Ross Messinger and John Pulley \\ The Boeing Company \\ Huntington Beach, California
}

\begin{abstract}
For
44 th AIAA/ASME/ASCE/AHS/ASC

Structure, Structural Dynamics, and Material Conference Special Session: Cryogenic Propellant Tanks and Integrated Structures for a Next Generation Reusable Launch Vehicle
\end{abstract}




\section{Outline}

Reusable Cryogenic Tanks

- Tank Test Article

- MSFC Test Facility

- Test Plan

- LN2 Pre-test series

- LH2 Cyclic Test

- Repair

- Burst Test

- Post-Test Evaluation 


\section{Tank Structural Gonfiguration}

\section{Heritage Rockwell SSTO}

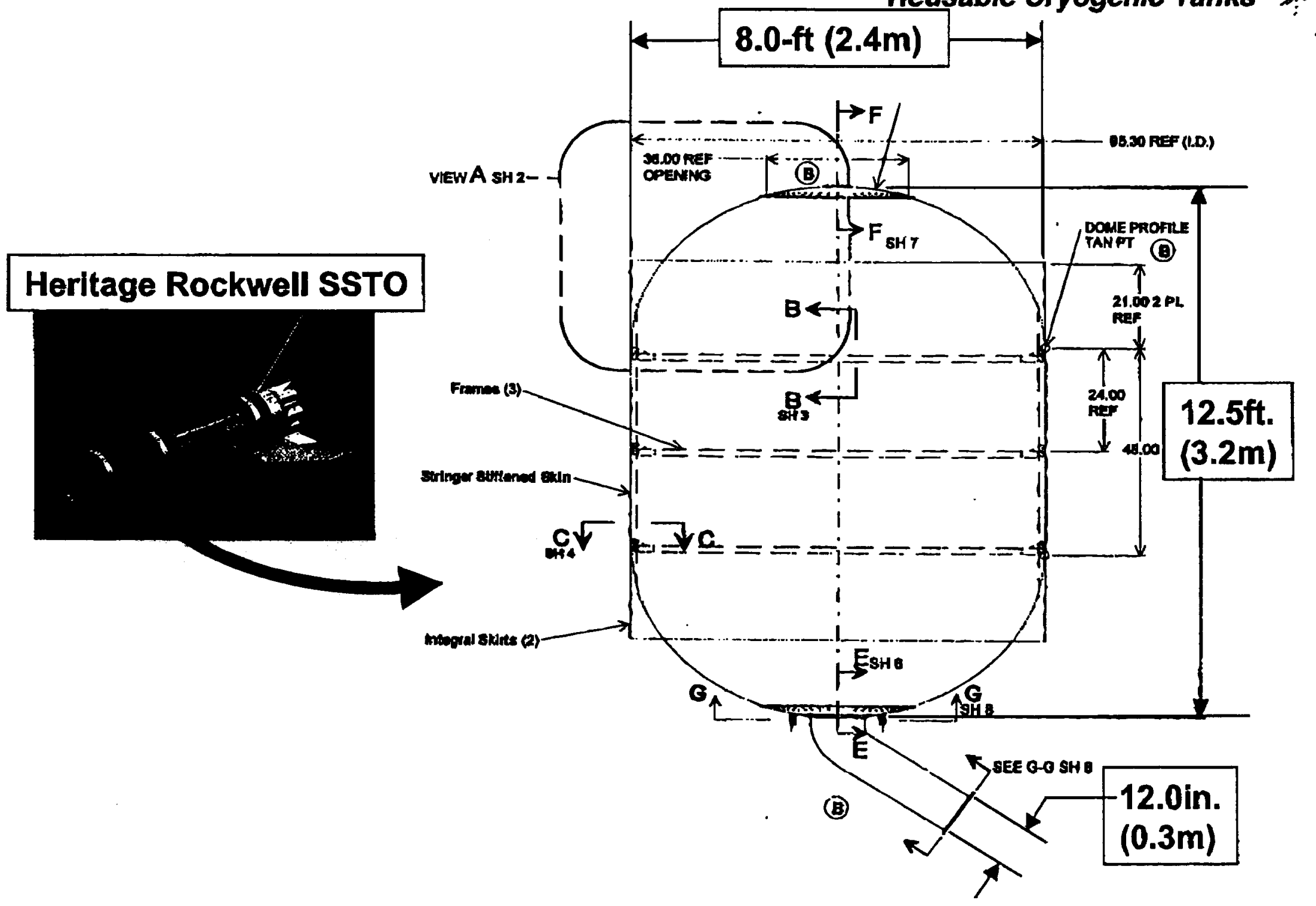

Reusable Cryogenic Tanks 


\section{As-Built Internal Details of Structure}

Reusable Cryogenic Tanks

\section{FRAME SPLICE}

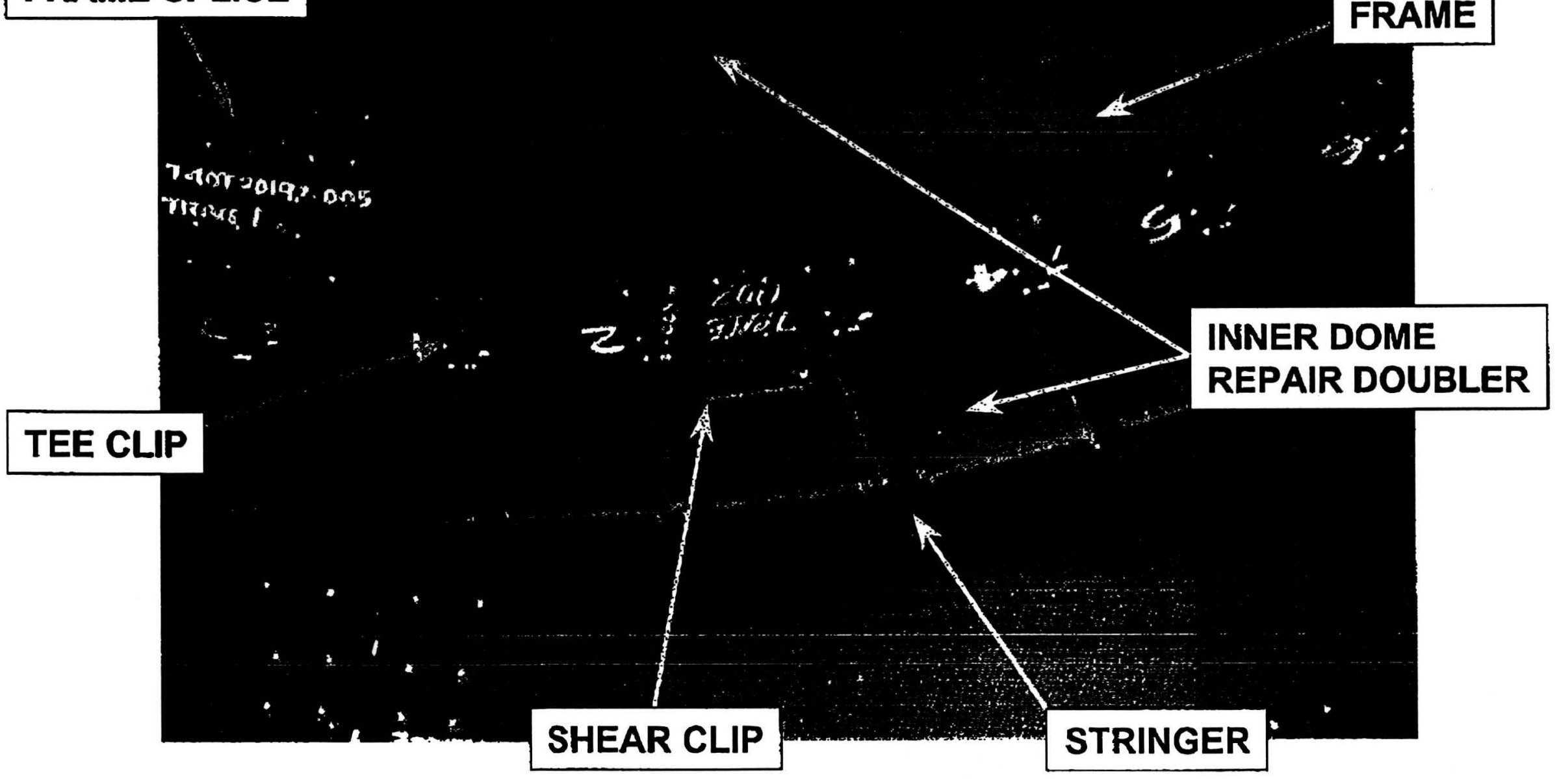




\section{TPS Arrangement In Heated Area of Tank Wall}

Reusable Cryogenic Tanks
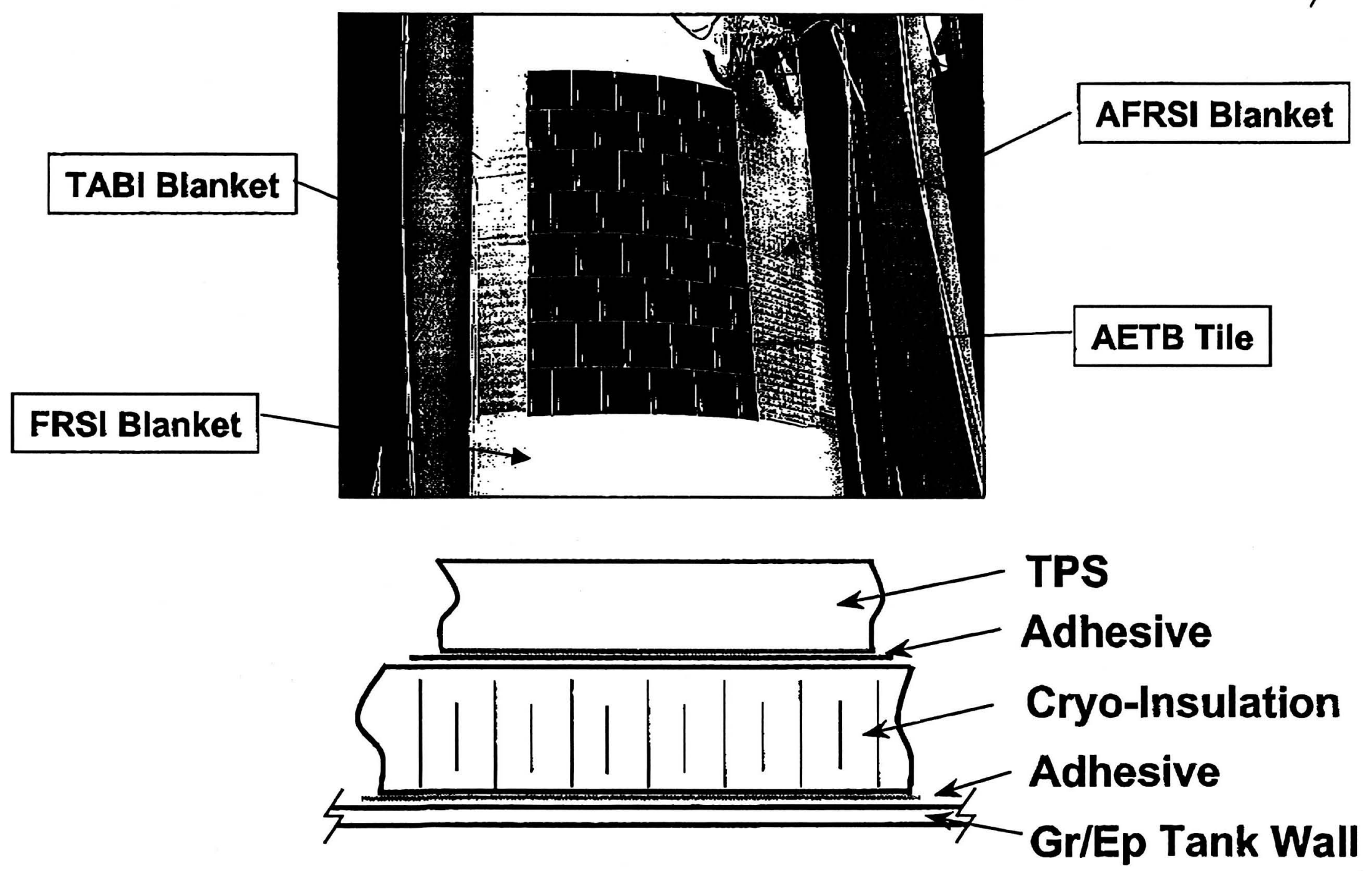


\section{MSFC Gryogenic Structure Test Facility}

Reusable Cryogenic Tanks

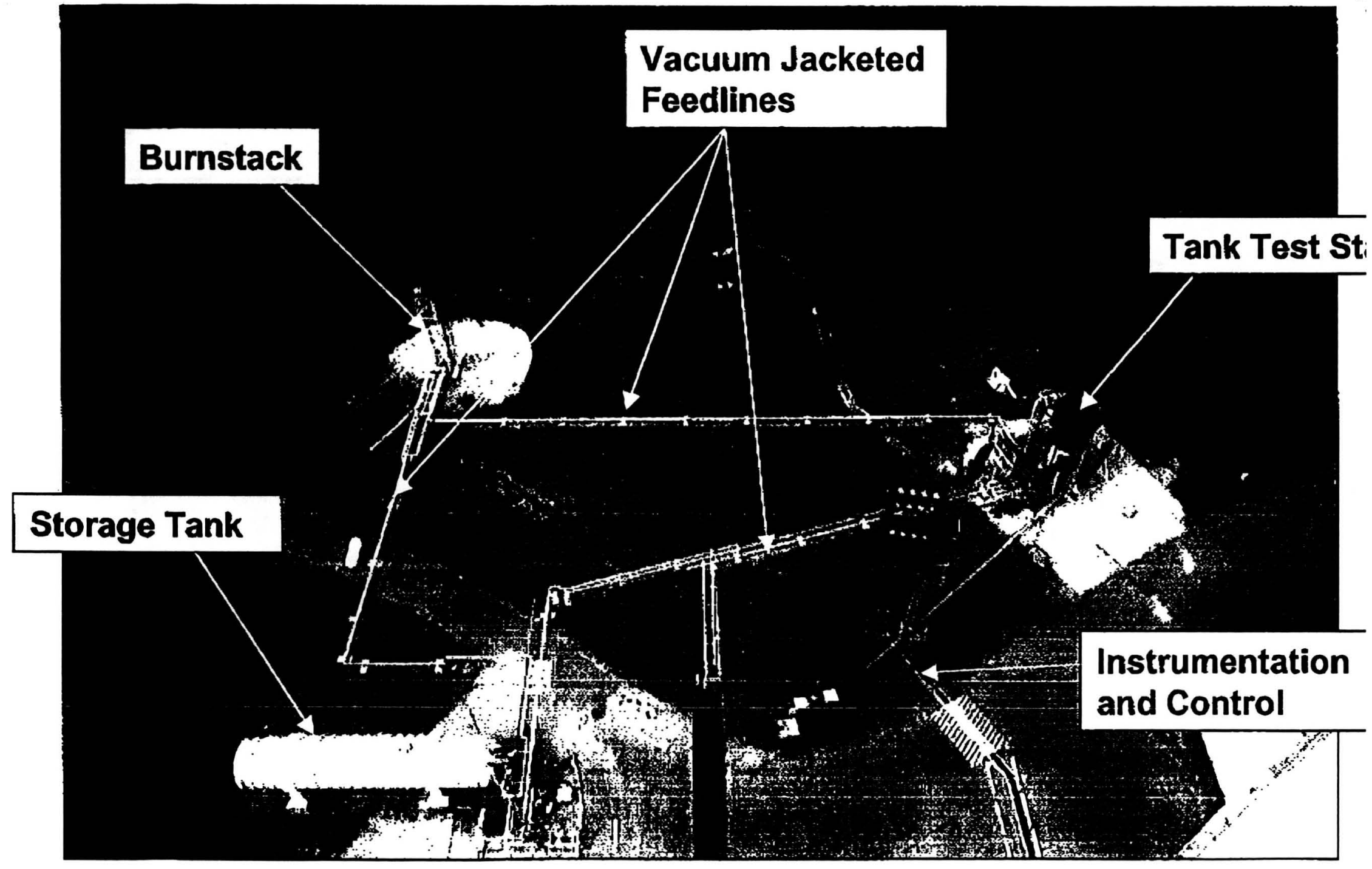




\section{8-ft Tank Test Setujp}

Reusable Cryogenic Tanks

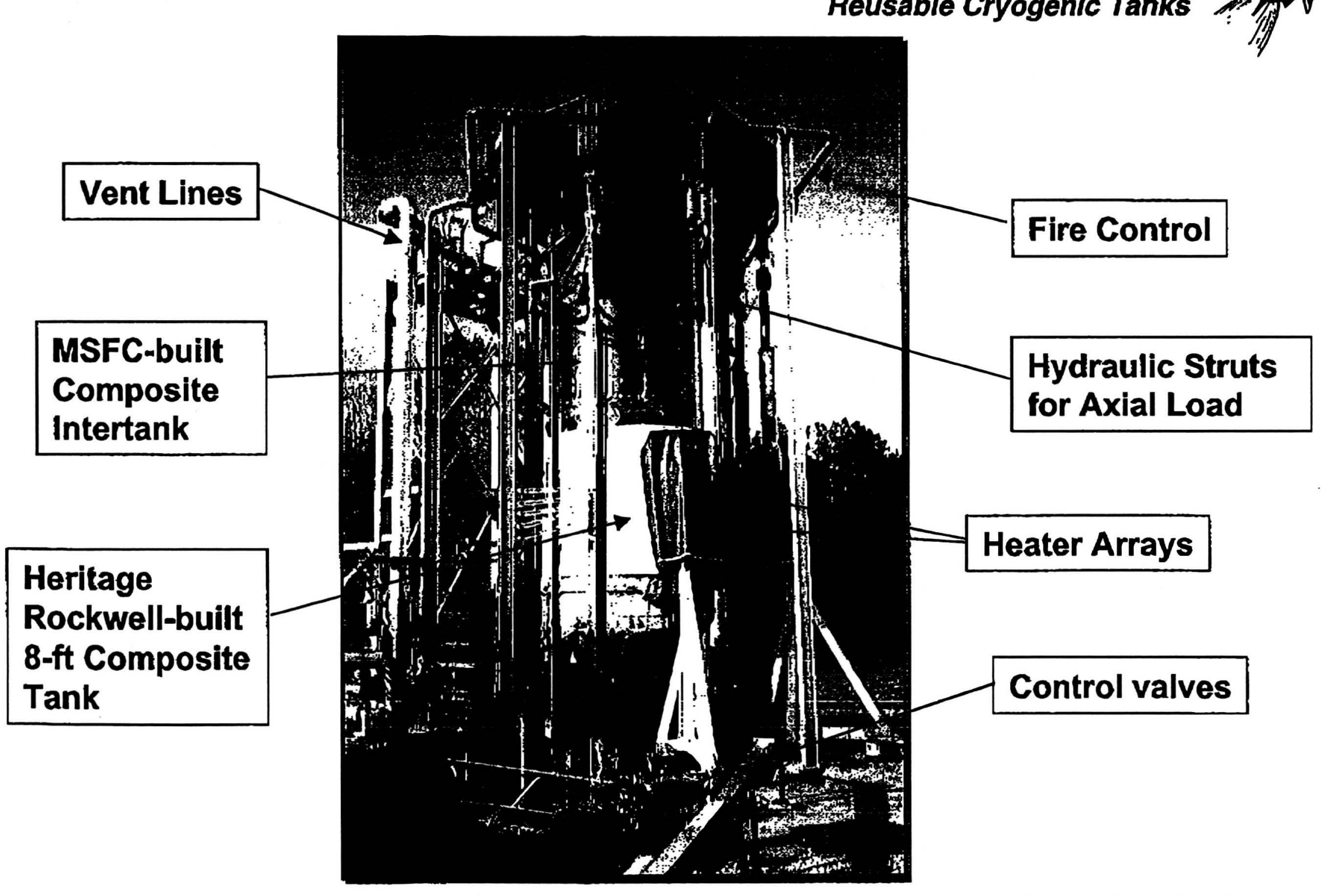

Integrated Defense Advanced Sysfems

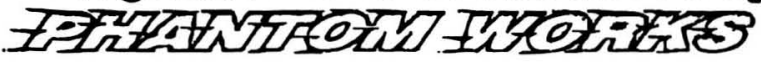




\section{Gyclic Test Plan and Accomplishments}

- Eight LN2 Pre-tests completed

- Cold shock

- Proof pressure (LN2)

- Ascent axial load

- Landing axial load

- 10 simulated LN2 cycles

- 26 of 200 LH2 Test cycles completed

- Fill and pressurize to over $\mathbf{4 0}$ psi

- Apply over $600 \mathrm{lb} / \mathrm{in}$ axial launch load

- Reduce pressure and load

- Apply heat to TPS surface (Entry)

- Apply over $800 \mathrm{lb} / \mathrm{ln}$ axial landing load

- Repeat 


\section{Visual Inspection of Tank Interior After 5 Gycles}

Reusable Cryogenic Tanks

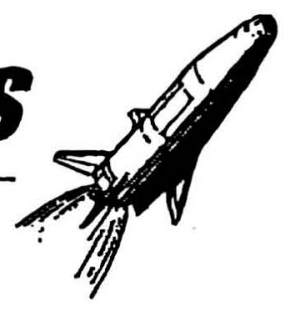

- With the sump cover off, an inspection of the inside of tank was performed

- No visually apparent anomalies were observed in the tank skin

- A "tap test" of the bond of each of the 60 stringers from the lower end to the mid frame revealed no obvious soft areas or disbonds

- Visual inspection of each of the tension and shear clips common to the lower frame showed no clip or fastener failures or apparent movement

- While not conclusive of tank health, no change in tank appearance was evident through 5 cycles

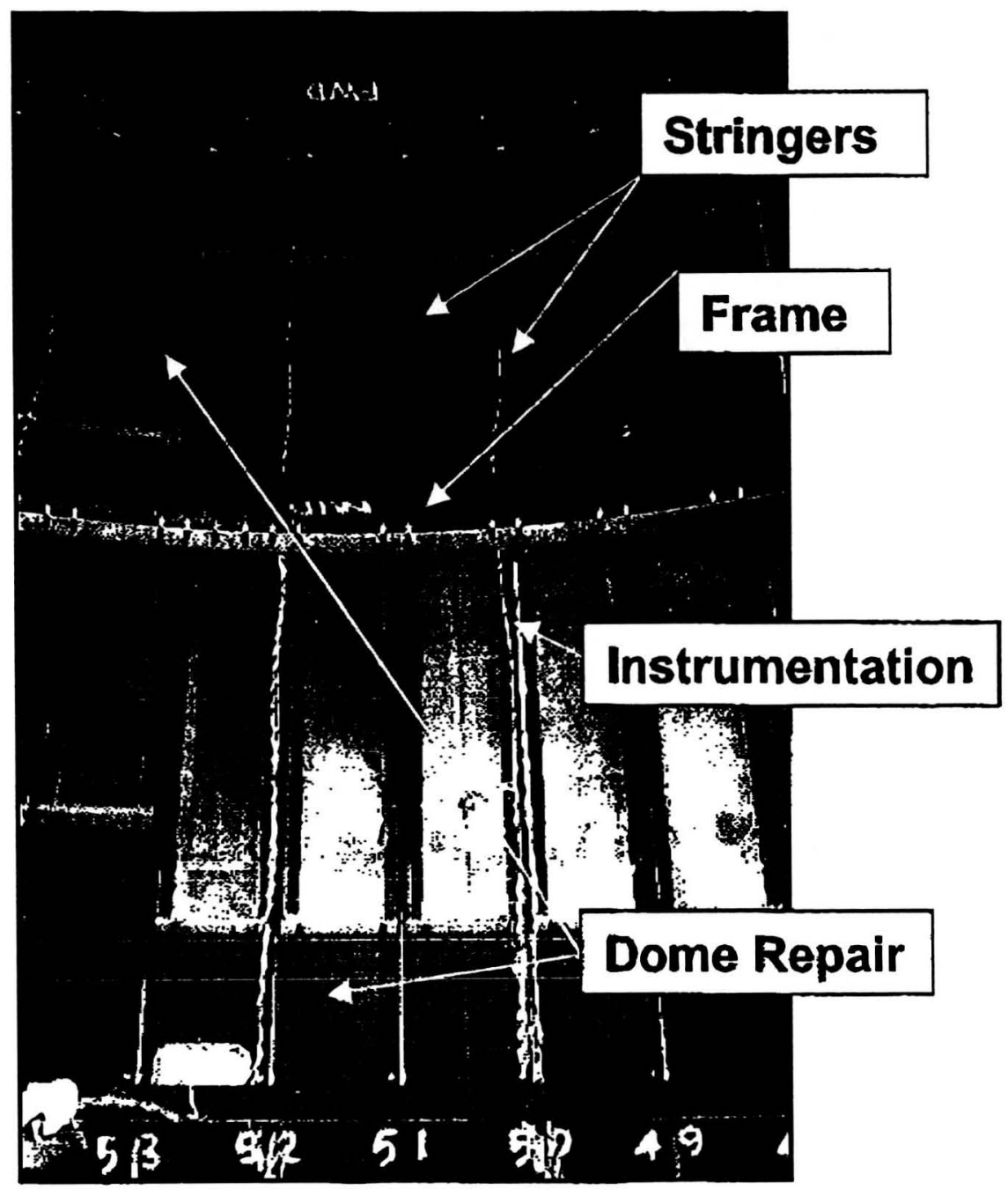




\section{Strain Data}

Reusable Cryogenic Tanks

- Large translation of the strain data was observed from some gages but not others, but since the data was linear, the behavior was concluded to be a gage or callbration issue rather than a structural problem

- Only four gages survived through all 26 LH2 cycles and burst test
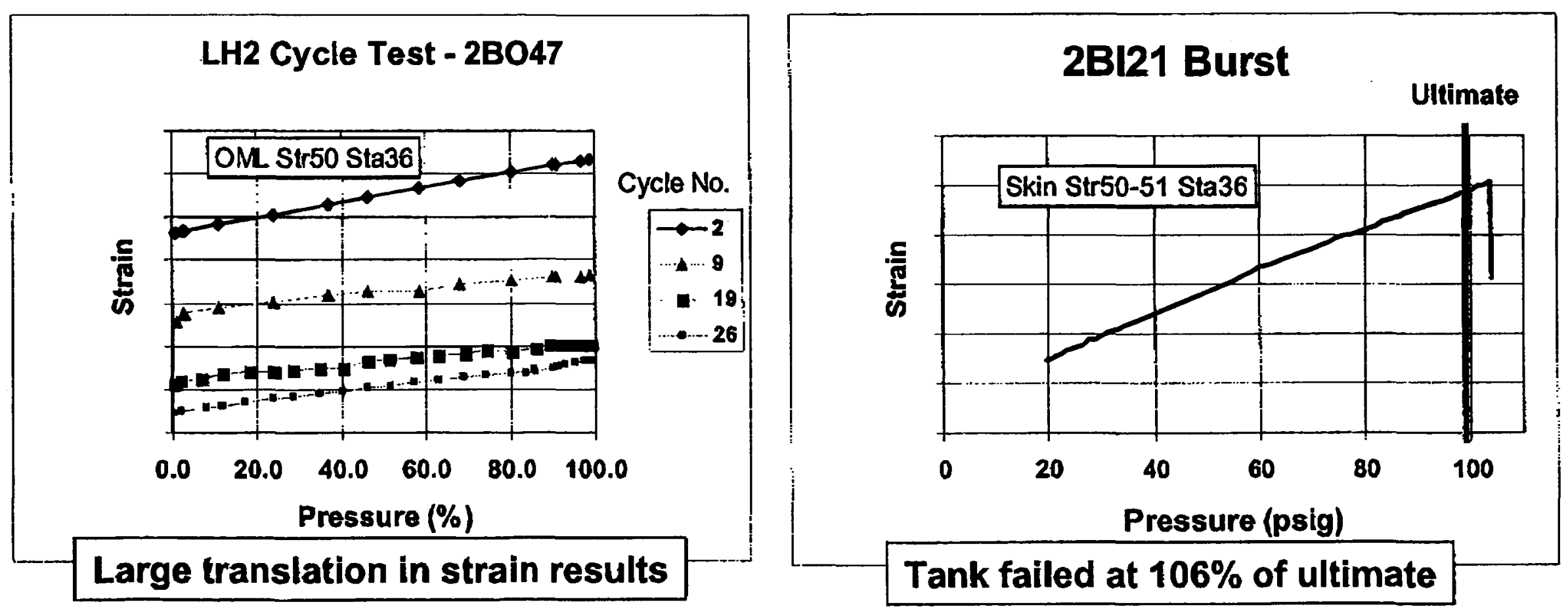

Integrated Defense Advanced Systems

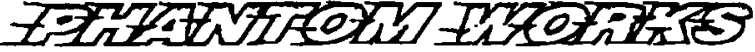




\section{TPS Temperature Data}

Reusable Cryogenic Tanks

- Thermal data obtained on wall, within TPS, within insulation, and at all interfaces

- Adhesive bondline temperatures generally remained within established maximum and minimum limits

- Cryopumping, caused by liquid air evaporating away from the tank wall surface and blowing through the insulation, was evident locally
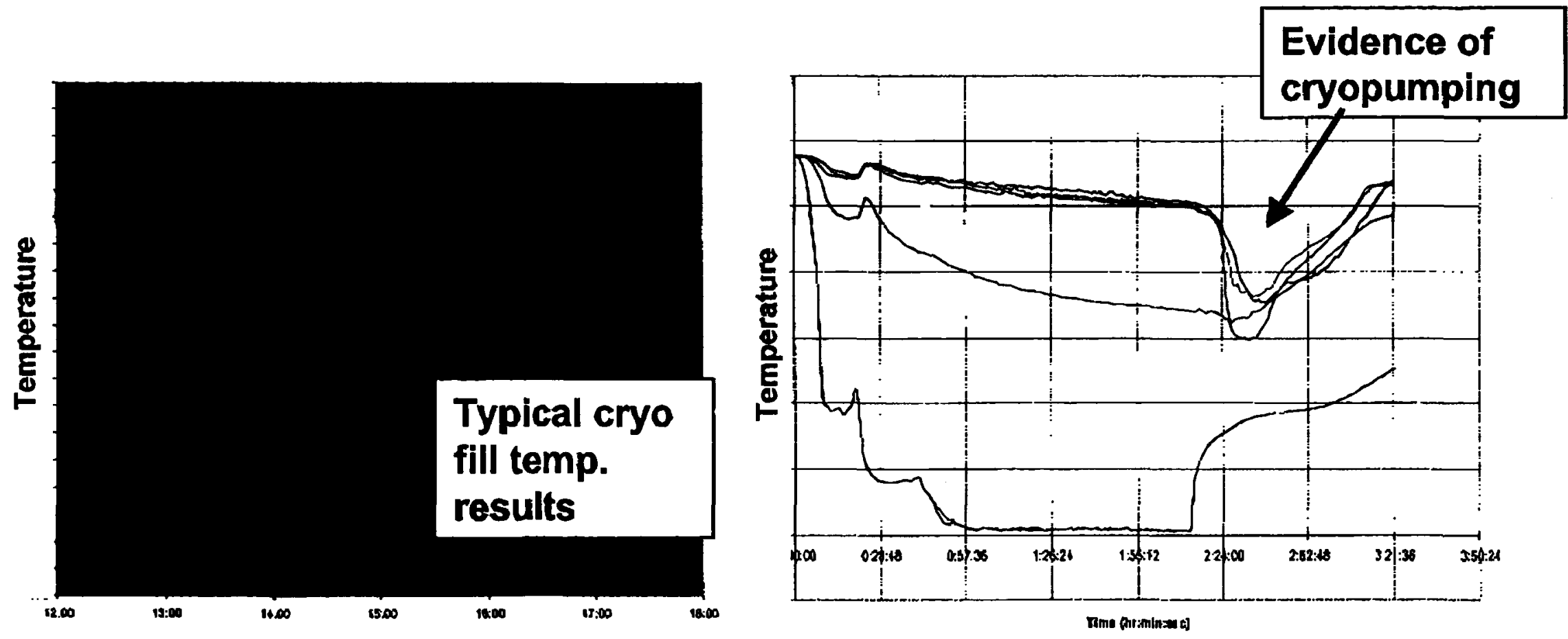

Integrated Defense Advanced Systems

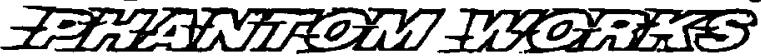




\section{Acoustic Emission Data}

Reusable Cryogenic Tanks

- Significant number of AE signals recorded during each LH2 or LN2

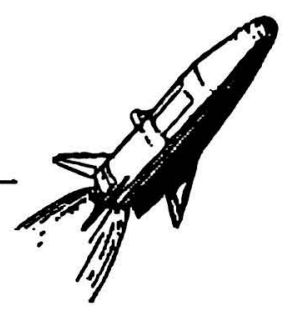
filling due to cold shock induced thermal stresses

- Tank pressurization (tension membrane load) caused a large number of AE hits

- Matrix cracking or crazing monitored at the beginning of the test series, with no structural integrity damage

- Fewer AE signals were detected during each subsequent equivalent cycle (Kaiser effect)

- A distinct peak of AE hits occurred when the pressure increased from the cyclic test pressure to burst pressure
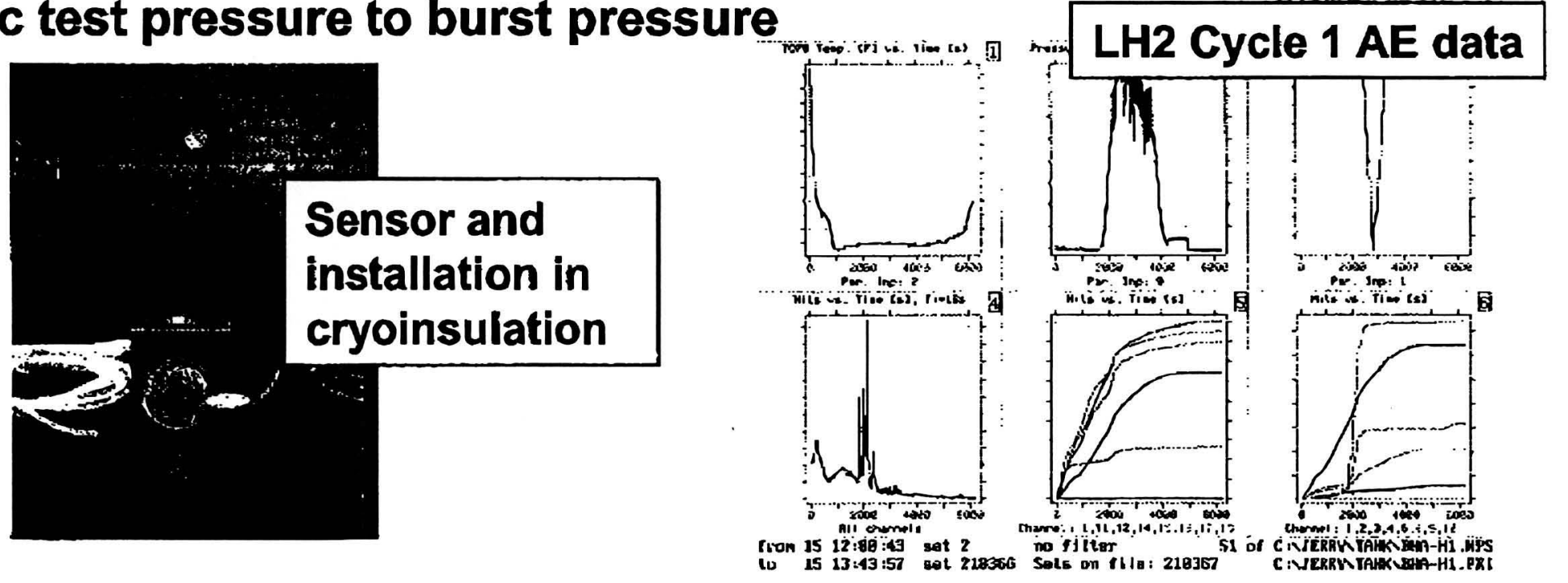

Integrated Defense Advanced Systems 


\section{Leak Detection and Repair}

Reusable Cryogenic Tanks
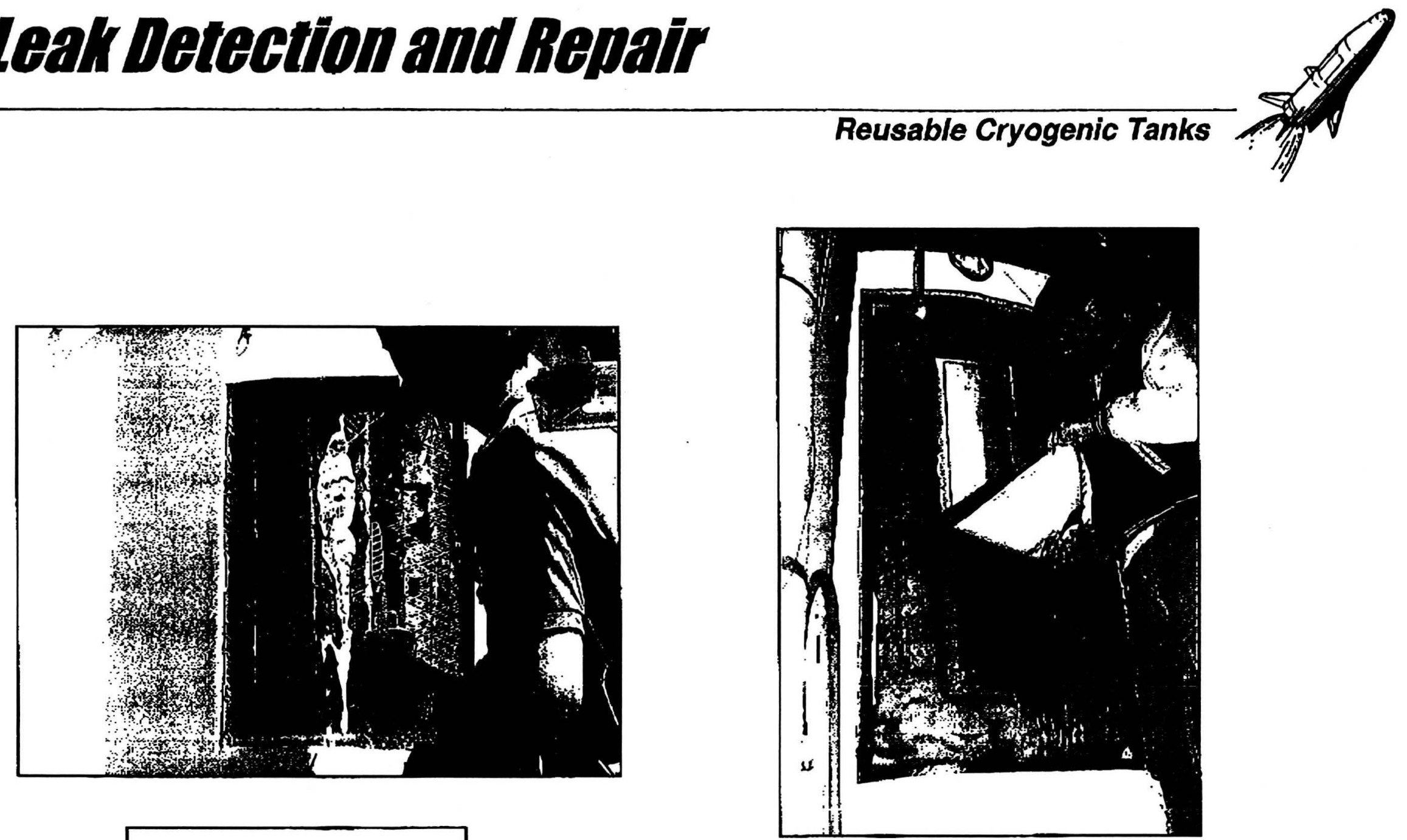

Bubbles Indicate

Leak Location

Vacuum bag being removed from external patch along stringer 51. 


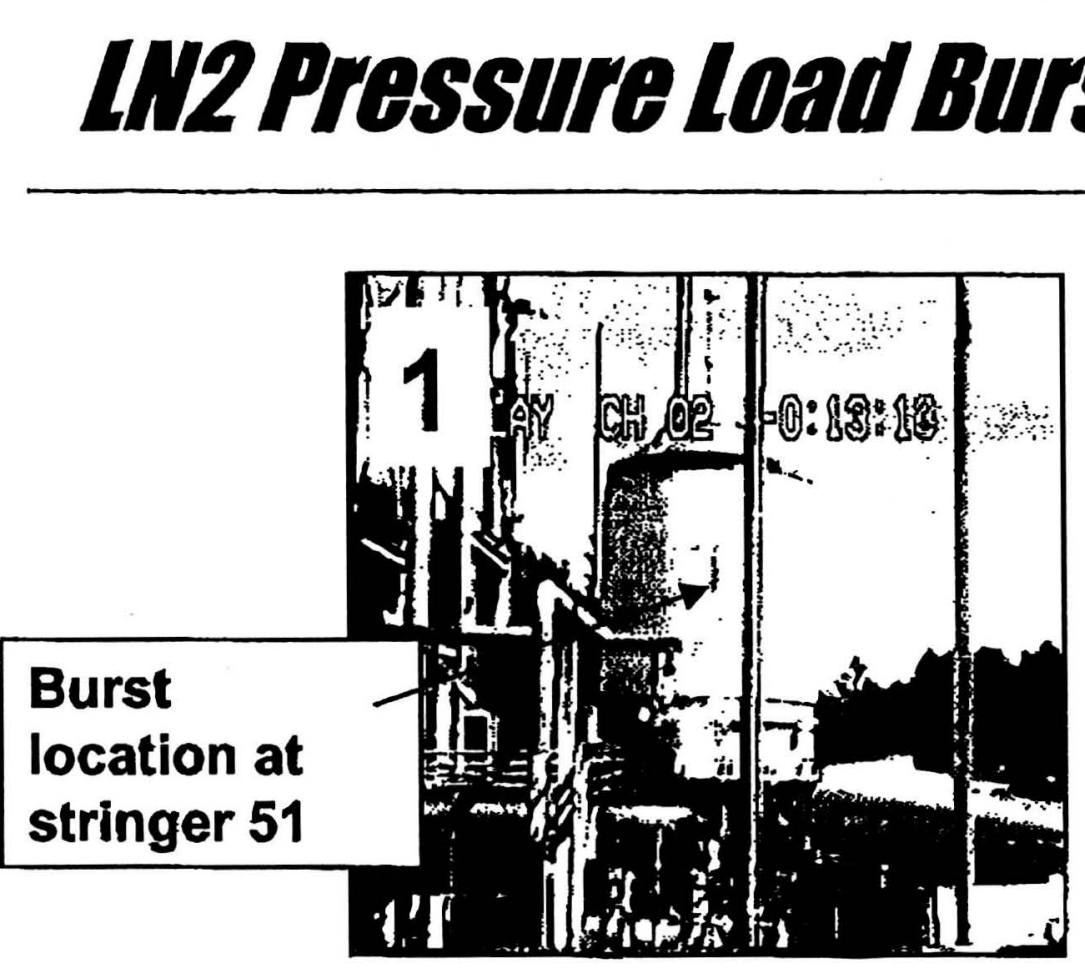

\section{Test}
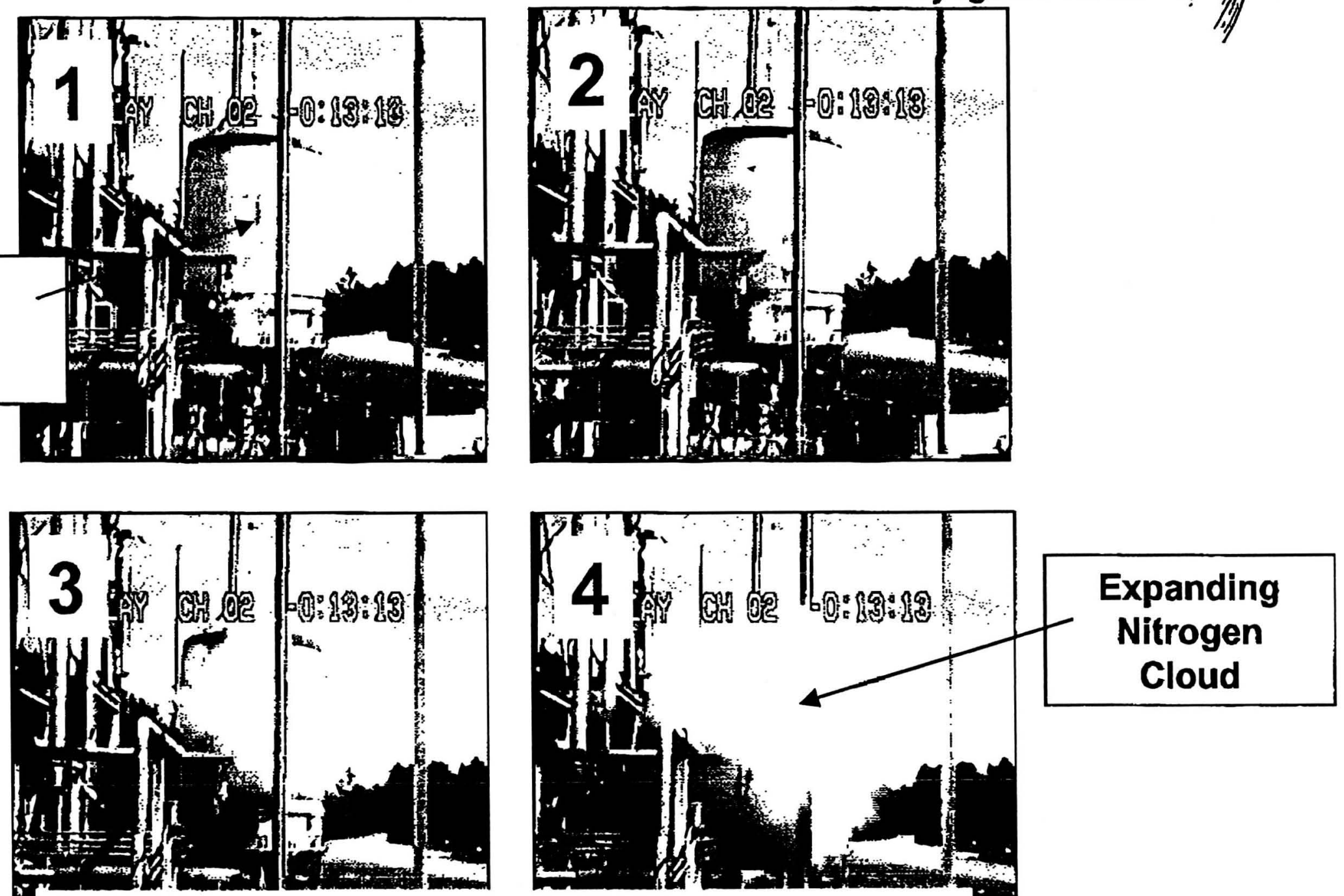

Burst occurred at $106 \%$ of ultimate) 


\section{Uttimate Load Test Failure Location}

Reusable Cryogenic Tanks

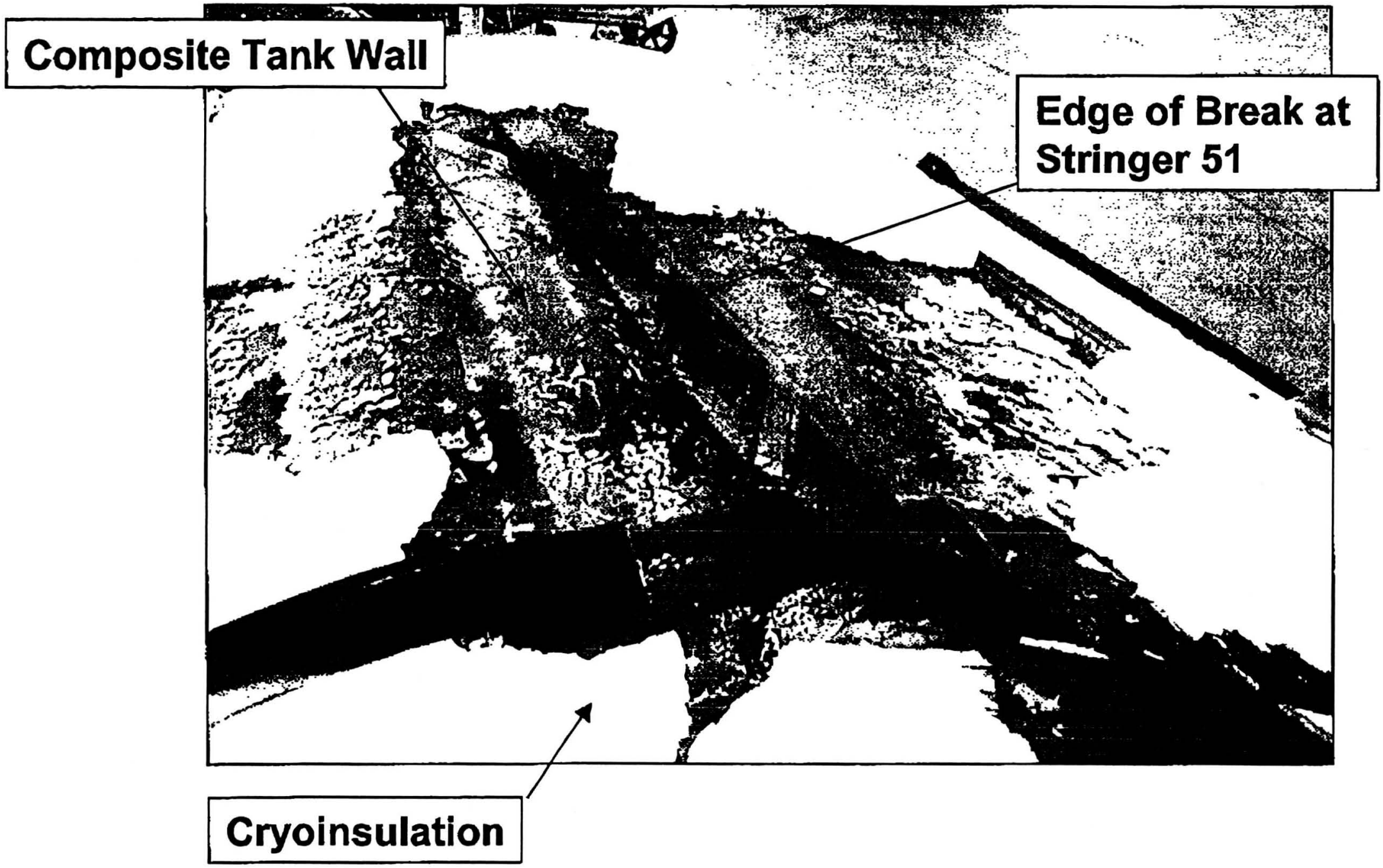




\section{Tank Dissection for Post-test Amalysis}

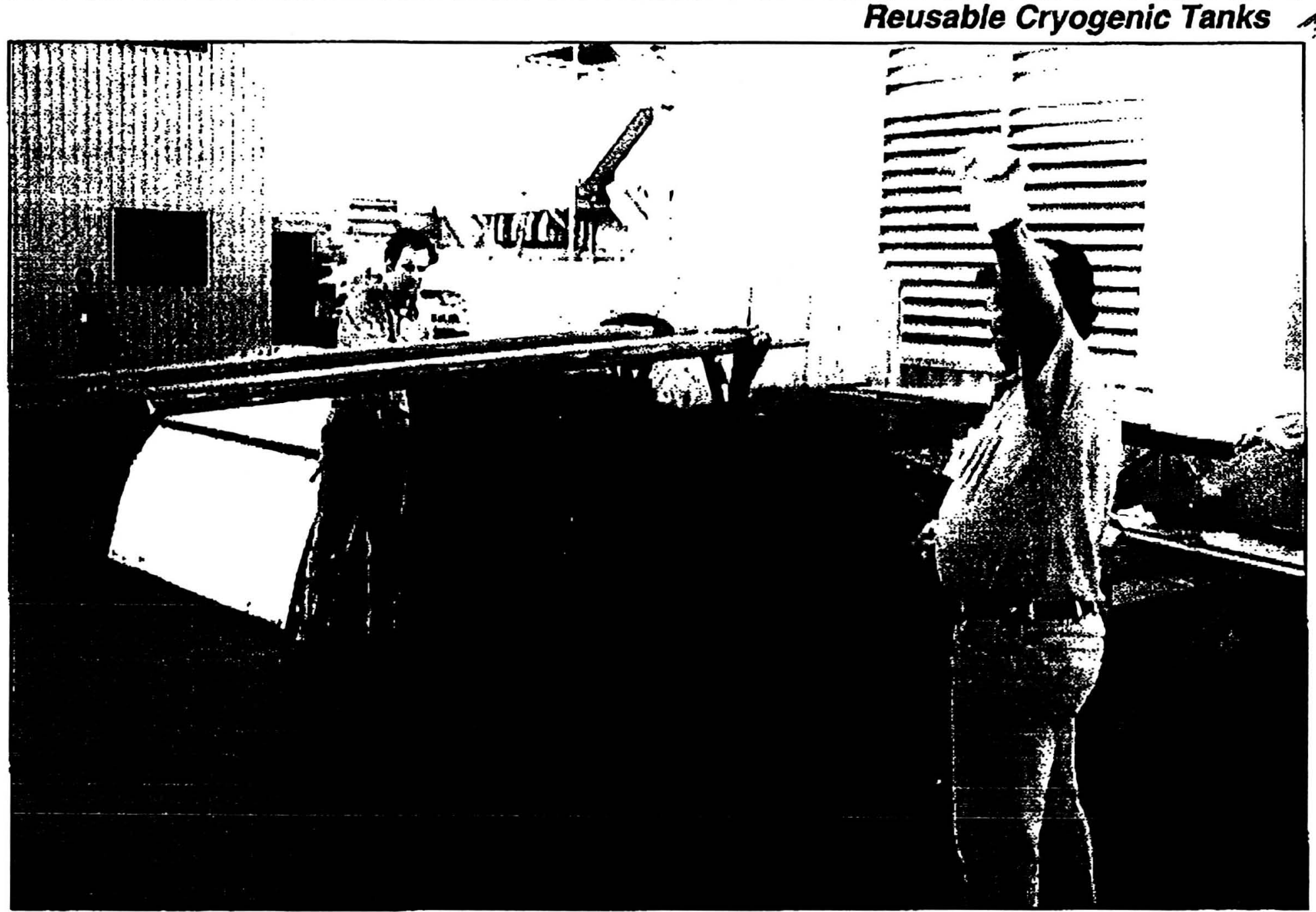




\section{Post-Lest Evaluation}

Reusable Cryogenic Tanks

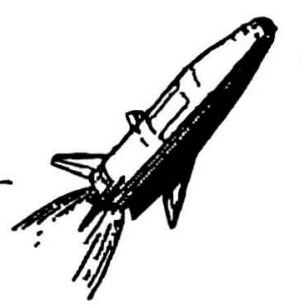

- Microscopy and C-scans revealed good tank wall consolidation

- Minimal microcracking (max. 2-ply depth) in the tank wall were found

- Blade-stringers were cracked in noodle area (probably due to thermal stresses)

- Some stringer flanges dis-bonded from the tank wall (probably due to burst test)
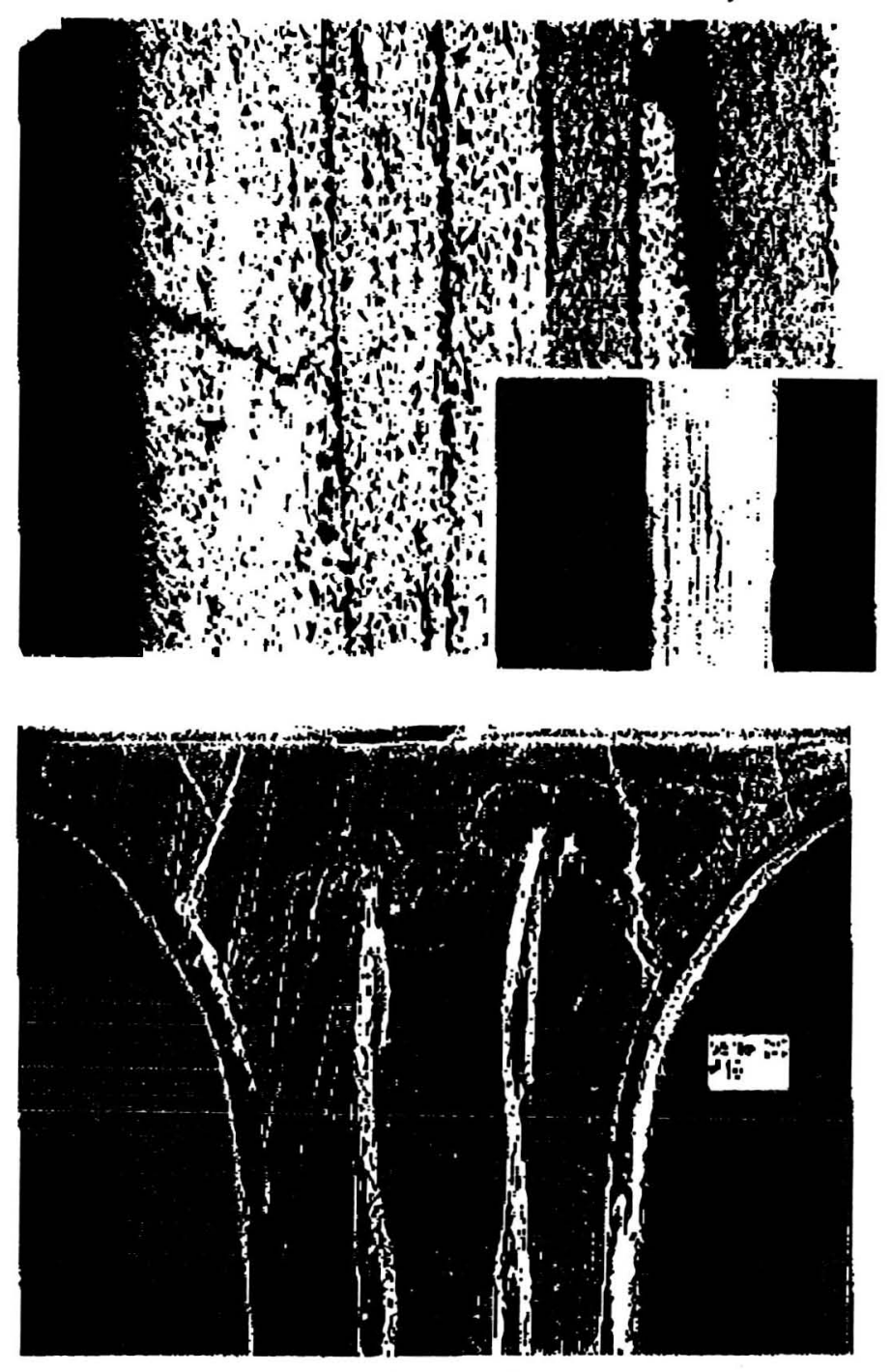


\section{Gonclusion and Recommendations}

Reusable Cryogenic Tanks

- Designed, built, and cyclic tested flight-weight graphite/epoxy LH2 tank under NASA MSFC Cooperative Agreement

- Integrated structure, cryo-insulation and TPS system with SHM instrumentation successfully demonstrated

- Eight LN2 Pretest Series tests completed

- 26 LH2 simulated mission cycles completed

-Burst test demonstrated robust design

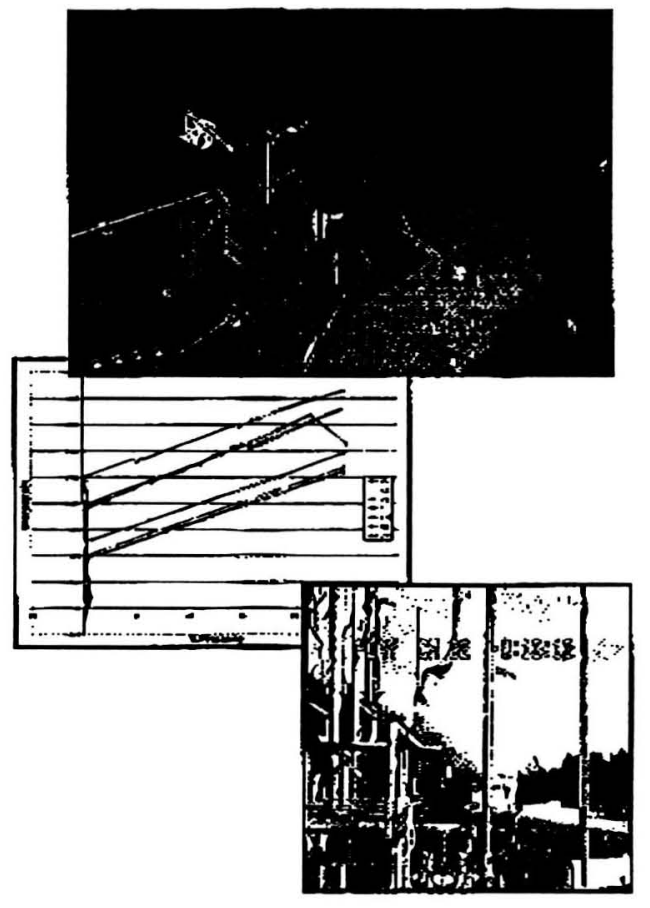

- Next building block in development of composite cryotanks for $R L V s$ is fabrication and cyclic test of an even larger tank, with integrated wing and thrust structure, to demonstrate low-cost producibility and operability, and long-life, complex-loading capability 